\title{
The effect of physical activity on sex hormone levels in women. Implications for breast cancer risk
}

\author{
Kinga Słojewska
}

Faculty of Health Sciences, Department of Environmental Health, Doctoral School of Medical and Health Sciences, Jagiellonian University Collegium Medicum, Krakow, Poland

Breast cancer is the most commonly diagnosed neoplastic disease in women, which leads to a significant deterioration in the quality of life and a reduction in the ability of women to function normally in everyday life. The main risk factor for breast cancer in both premenopausal and postmenopausal women is exposure to high levels of endogenous estrogen. It takes many years for neoplasia to develop, but lowering estrogen levels has been observed to reduce the risk of both a new diagnosis and recurrence of breast cancer. Observational studies have found that exercise reduces the level of bioavailable sex hormones, and thus may reduce the risk of developing breast cancer. Currently available evidence clearly shows that adequate levels of physical activity are associated with a $25-30 \%$ reduction in the average risk of breast cancer in women and play a role in its treatment.

This review summarizes the data available in the literature on the effect of physical activity on the level of sex hormones in women, while presenting the biological mechanisms underlying the relationship between physical activity and the development of breast cancer. This issue requires further research, but already now, extensive educational campaigns are needed which can be aimed at young women to inform them on the possibility of significantly reducing their risk of breast cancer by introducing physical activity into their everyday lives.

Key words: exercise, gonadal steroid hormones, estrogen, risk factors, breast cancer

\section{Physical activity and sex hormone levels}

The results of many observational and experimental studies confirm that there is a relationship between lifestyle and the occurrence of many diseases, including cancer, and their prognosis $[1,2]$. The American Cancer Society's recommendations for a healthy lifestyle include a healthy eating pattern, at least 150 to 300 minutes of moderate-intensity exercise per week, limiting sedentary behavior, maintaining a healthy body weight and avoiding drinking alcohol [3]. Among women, one of the most common cancers is breast cancer and in 2020 it accounted for $25.4 \%$ of all newly diagnosed cancers. [4, 5].

\section{Breast cancer risk factors}

There are a few modifiable factors that influence the risk of breast cancer, including: being overweight or obese [6], improper diet and alcohol consumption [7], lack of physical activity [8] and prolonged exposure to steroid hormones [9]. Non-modifiable or less modifiable risk factors include: age, reproductive factors [10], such as early age of first menstruation, late age of menopause, late age of first term pregnancy, infertility $[11,12]$, as well as a family history of breast cancer [13].

\section{How to cite:}

Słojewska K. The effect of physical activity on sex hormone levels in women. Implications for breast cancer risk. NOWOTWORY J Oncol 2021; 71: 383-390. 


\section{The role of sex hormones in the development of breast cancer}

As the risk of breast cancer in women increases with early first menstruation and late menopause, estrogen and progesterone are believed to play a major role in breast carcinogenesis [14]. Endogenous sex hormones, especially estrogens, appear to be involved in cancer initiation, promotion and progression $[12,15]$, therefore long-term exposure to high hormone levels is considered one of the major risk factors. The role of progesterone in the development of breast cancer is less clear-cut, but there is evidence that progesterone may augment the mitogenic effects of estradiol [16].

It is also considered that progesterone has an antiproliferative effect on breast cells in premenopausal women. The results of research on animal models indicate that progesterone contributes to the proliferation of the endothelial gland and sensitizes cellular cancer cells to growth factors [17-19]. The results of the Million Women Study survey show that women who used progesterone combined with estrogen as hormone replacement therapy had a significantly higher risk of breast cancer compared with women taking only estrogen [20]. There are also epidemiological data indicating the protective action of progesterone in the development of breast cancer [18, 20].

In addition, sex hormone binding globulin (SHBG) is also considered to play a role in breast carcinogenesis. It regulates the bioavailability of estradiol and testosterone [22], inhibits cell growth and counteracts apoptosis in breast cancer cells that have estrogen receptors (ER+) [23].

\section{Biological mechanisms}

Current evidence indicates that physical activity is associated with a 25-30\% reduction of the average breast cancer risk in women $[1,24]$. Underlying biologic mechanisms mediating the association between physical activity and breast cancer are not fully understood, but there are several likely biological mechanisms at play. It is assumed that physical exercise can lead to a reduction in breast cancer risk through both hormonal and non-hormonal mechanisms. Physical activity reduces the level of biologically available sex hormones, which can lead to a reduction in the risk of tumors associated with hormones, including breast cancer. Physical exercise also affects glucose metabolism, reducing the concentration of other hormones and growth factors, including insulin and insulin-like growth factor (IGF-1) $[25,26]$. Inter-population variation in ovarian steroid levels and exposure to estrogens throughout life is associated with a variation of breast cancer risk. The causes of such variation are differences in physical activity and energy expenditure [27].

In the prevention of breast cancer, body weight control is particularly important. Physical activity helps to reduce the total body weight and intra-abdominal fat. In addition, it strengthens immunological functions, inhibiting tumors, increases the number of macrophages, NK cells and cytokines, and also regulates the activity of free radical inhibitors and increases the concentration of biogenic antioxidants [28].

\section{Physical activity and the level of hormones in women before menopause}

To date, several studies on breast cancer have examined healthy premenopausal women [29]. However, it is suspected that the hormonal exposition before menopause has an impact on the risk of incidence of breast cancer after menopause $[30,31]$, and the risk of breast cancer increases with an early first menstruation and late menopause [14]. This suggests that the exposure to high concentrations of sex hormones during this period can play an important role in the initiation and development of breast cancer.

\section{Moderate physical activity}

The physical activity in adulthood is associated with a reduced risk of breast cancer, even with a moderate level of physical activity, including occupational physical activity [32, 33]. In a study of young women with premenstrual syndrome, it was observed that the level of estradiol and progesterone decreased by $23.9 \%$ and $41.2 \%$ respectively when compared to the control group after a series of 3-month aerobic training [34]. The risk of breast cancer is also smaller in women who have practiced recreational physical activity before, as well as among women who were more active than their peers at the age of 10-12 [35].

\section{Physical activity combined with a caloric deficit}

Exercise interventions that are accompanied by the energy deficit, lead to changes in the circulation of estrogens in women before menopause [36]. Research results show that moderate aerobic physical activity in combination with calorie limitation may result in a significant reduction in exposure to estrogens and progesterone and transient increase in SHBG [37]. In one study, young women before menopause perform moderate aerobic exercises for 16 weeks after 150 minutes for week, but without changing weight. Sex hormone or SHBG levels have not changed significantly. However, the reason for the lack of the expected effect could be slight changes in body composition. Perhaps a longer exercise intervention would have had different results. It is also possible that the detection of changes would be possible when collecting samples to analyze closer to the ovulation date when the estradiol level is higher. [38].

However, there is also evidence that work-related energy expenditure does not have to lead to a negative energy balance to cause inhibiting reproductive functions in women. Even in women whose body weight does not change as a result of intensive training, there may be disorders in cycles $[36,39,40]$. In addition, in meta-analyzes of randomized control trials on the impact of physical activity on the level of sex hormones in women, it was observed that a decrease in total estradiol was associated with weight loss after intervention; a drop in free 
estradiol was not associated with weight loss. This result suggests that physical activity without associated weight loss, can also lead to the suppression of estradiol levels in women [41].

It also assumes that a certain level of activity is needed to induce a protective effect in relation to breast cancer. The relationship between training load and ovarian function was observed and it suggests that the hormonal response also depends on the type and intensity of the workout. In addition, the amount of the energy deficit is linearly related to the overall frequency of the occurrence of menstruation disorders $[42,43]$.

\section{The role of estrogen metabolites in carcinogenesis}

Estrogen metabolites can initiate the carcinogenesis process, which is why they are considered as breast cancer risk markers. In many studies, it was found that a higher 2-OHE1 ratio to $16-O H E 1$ is associated with a reduced risk of breast cancer $[44,45]$. In addition, women before menopause, who declared a higher level of physical activity, had a higher ratio of the estradiol metabolites 2-OHE1 and 16-OHE1 than women who declared that they exercised less [46]. However, in some studies, improving oxygen capacity $\left(\mathrm{V}_{\mathrm{O} 2 \mathrm{max}}\right)$ and slight changes in the composition of the body did not have a significant impact on estrogen metabolites $[47,48]$.

\section{Physical activity and the level of sex hormones in women taking part in high intensity training}

Physical activity can cause hypomenorrhoea and amenorrhea, which is observed in 6-79\% of women-athletes [49, 50]. It can also cause anovulatory cycles and/or a reduction of sex hormone concentrations without affecting the regularity of the cycles. Nutrition disorders, irregular menstruation, and bone loss are part of the clinical condition called "triad of women-athletes"[51]. Insufficient calorie consumption in relation to energy expenditure during exercise leads to energy deficiency and stimulates compensation mechanisms, such as weight loss or energy saving, causing inhibiting reproductive functions, including a reduced level of estrogen [52]. The intensity of exercises is the decisive factor. In many studies, participants who intensively trained, suffered significant dips in estrogen and progesterone levels, sometimes leading to the lack of menstruation. [53, 54].

In $70 \%$ of officers' training participants who had regular menstruation, as a result of training menstruation became more irregular. The levels of the tested hormones, including estradiol, decreased after training, but did not differ between participants with normal menstruation and those with irregular menstruation [55].

\section{The effect of physical activity on women at increased risk of breast cancer and breast cancer survivors}

Physical activity, both before diagnosis of primary breast cancer and after diagnosis, has a beneficial effect on the survival of women [56]. There was an inverse relationship between increased levels of physical activity after diagnosis and all-cause mortality and death from breast cancer, as well as a higher risk of death among women who had decreased levels of physical activity after diagnosis. Women who increased their physical activity after diagnosis had a $45 \%$ lower risk of death compared to inactive women both before and after diagnosis $[57,58]$. Observational studies have also shown that women with breast cancer who are overweight or who gain weight after diagnosis are at a higher risk of breast cancer recurrence and death compared to women who are not overweight [59].

The results of meta-analyzes of prospective cohort studies confirm that adequate physical activity may be an important intervention to reduce the number of deaths and recurrences of breast cancer in women $[60,61]$.

There is also growing evidence of the active role of adipose tissue in tumor initiation and growth. The local production of estrogen in the tumor is believed to stimulate the growth of hormone-dependent breast cancer. In addition, estrogen metabolism is regulated differently in the adipose tissue of women with or without cancer. In one study, the concentration of estradiol in breast adipose tissue was lower in women with cancer than in the control group, while the levels of serum hormones did not differ [62].

A 6-month lifestyle intervention was performed in overweight or obese women who were at high risk of breast cancer and included dietary modification and exercise. As a result of the intervention, a reduction in obesity was accompanied by a reduction in serum estrogen levels. However, statistically significant decreases in serum estradiol and estrone levels were not detected in the period of active adipose tissue loss, but instead 3 months after the intervention, in the period of body weight stabilization [63].

Studies have also shown that in healthy premenopausal women at high risk of breast cancer, the levels of estradiol and progesterone decrease or remain unchanged due to exercise [64].

\section{Lifestyle and the risk of breast cancer}

\section{Habitual physical activity}

Habitual physical activity includes daily physical activity, work, housework, childcare, walking and exercise, and according to research results, it is significantly related to the concentration of estradiol in saliva. In women with low habitual physical activity, mean estradiol levels are $21 \%$ higher than in the group of highly active women and almost 18\% higher than in women with moderate activity [27] [65]. Also, seasonal increases in the intensity of physical work by Polish women living in the countryside may be associated with a decrease in the level of progesterone by almost 25\% [39]. It has also been observed that postmenopausal women who have never used hormone replacement therapy had a reduced risk of exercise-related 
breast cancer. These results suggest that daily, moderate-intensity physical activity, such as walking, may protect against breast cancer [66].

\section{Healthy lifestyle}

In a study assessing the relationship of a healthy lifestyle, which included smoking, diet, and physical activity, a significant inverse relationship was found between a healthy lifestyle, assessed using validated questionnaires, and the chance of developing breast cancer. This relationship was significant in postmenopausal women, but no relationship was found in the group of premenopausal women [67].

\section{Metabolic profile}

Low serum HDL-C cholesterol is associated with increased levels of free, biologically active estradiol throughout the menstrual cycle. Moreover, it was observed that women with high BMI ( $\left.\geq 23.6 \mathrm{~kg} / \mathrm{m}^{2}\right)$ and relatively high serum LDL/HDL-C ratio ( $\geq 2.08$ ) were exposed to significantly higher levels of free estradiol than other women [68]. For this reason, HDL-C levels may be a biomarker of breast cancer risk, especially useful in overweight and obese women.

\section{Tea and coffee consumption}

Catechins and theaflavins are the main ingredients of tea. It inhibit aromatase, an enzyme that catalyzes the conversion of androgens to estrogens, and as a result, estradiol production may be reduced in women of childbearing age who consume large amounts of tea. According to studies, women with a higher average daily intake of black tea have lower salivary estradiol levels compared to women who drink less black tea [69]. Coffee ingredients also exhibit estrogenic activity. Many studies have noted the potential uses of coffee in the treatment and prevention of cancer. Derivatives of cinnamic acid, terpenoids, and alkaloids contained in coffee, by inducing apoptosis, have a cytotoxic effect on breast cancer cells [70, 71].

\section{Birth weight and adult body composition}

In a study of young healthy women with regular menstrual cycles, it was shown that low birth weight $(<3.530 \mathrm{~g})$ combined with a large adult waist circumference $(>84 \mathrm{~cm})$ was associated with a $33 \%$ increase in free estradiol levels throughout the menstrual cycle compared with women of higher birth weight with the same waist circumference in adulthood. These results confirm that birth weight, which is a marker of pre-fetal conditions, in combination with energy availability and metabolism during growth and development, affect estrogen levels in the premenopausal period [72].

\section{Regular sleep}

Increased exposure to light at night, for example due to night shift work or shorter sleep times, can suppress melatonin production, which in turn can increase sex hormone levels. It was shown that the average level of estradiol in women who slept regularly was $60 \%$ lower compared to women with greater variability in their sleep schedule. These results suggest that sleep variability is significantly correlated with estradiol levels, while sleep duration does not show a statistically significant relationship $[73,74]$. High estradiol levels may also be associated with poorer sleep quality [75].

\section{Sedentary lifestyle}

The role of a sedentary lifestyle in estrogen metabolism has yet to be established, but existing evidence suggests that prolonged time spent sitting may lead to negative metabolic consequences, including increased central obesity and higher levels of endogenous estrogen $[76,77]$.

\section{Physical activity before menarche}

The date of the menarche is to some extent a modifiable feature. Studies have shown that competitive sport between the ages of 13-16 was associated with a later first menstruation compared to girls who did not exercise at that age. [78]. A meta-analysis of studies conducted on a group of athletes and people not practicing sports showed that in people practicing sports professionally in adolescence, the first menstruation occurred on average more than 1 year later compared to people not practicing sports [79].

\section{Physical activity and hormone level in postmenopausal women}

Menopause occurs, on average, around the age of 50 and is characterized by numerous hormonal changes. The postmenopausal period is associated with estrogen deficiency [80] and an increase in androgens [81]. There is also a reduction in urinary excretion of progesterone metabolites [82, 83]. These changes can lead to a rapid loss of muscle strength and bone mineral density, reduced aerobic capacity and weight gain. There is also an increased risk of developing a number of chronic diseases, including breast cancer [84].

The regulatory effect of exercise on women's hormone metabolism varies between pre- and postmenopausal women, and the mechanisms responsible for the protective effects of exercise are not yet well understood. It is believed that physical activity may lower the levels of circulating parent estrogens, estradiol and estrone [85]. In a study evaluating the relationship between physical activity and a sedentary lifestyle and postmenopausal estrogen metabolite levels, higher mean activity was significantly associated with lower urine estrogen levels and selected estrogen metabolites, while longer sitting time was significantly associated with higher estrogen levels and their metabolites [85].

Epidemiological studies compared hormone levels in women diagnosed with breast cancer to healthy controls. The results of these studies suggest that postmenopausal women with breast cancer had higher levels of estradiol and estrone than healthy postmenopausal women [86]. 


\section{The role of adipose tissue in the formation of estrogens}

In postmenopausal women, endogenous estrogen formation occurs mainly in adipose tissue by aromatizing the adrenal androgens to estrone - the main circulating estrogen - which is then metabolized [87]. There is convincing evidence that obesity, resulting in higher endogenous estrogen levels than in lean women, increases the risk of breast cancer in postmenopausal women $[88,89]$. This mechanism is biologically insignificant in the premenopausal period, when the ovaries are the main source of estrogen, and estrogen levels are many times higher than in the postmenopausal period.

In healthy, overweight, and obese postmenopausal women, higher levels of estrogens and androgens and lower concentrations of SHBG have been observed compared with lower body weight women $[90,91]$. It also seems that the relationship of body mass index (BMI) with breast cancer risk is largely limited to ER1/PR1-dependent tumors. With the increase in body weight in the postmenopausal period, a significantly increased risk of hormone-dependent ER1/PR1 breast tumors was observed [92].

Moreover, excess adipose tissue, especially abdominal fat, is positively correlated with insulin resistance. Prolonged hyperinsulinemia reduces the level of bioavailable sex-hormone-binding globulin (SHBG) and increases the levels of circulating estrogens and androgens, which may further contribute to the formation of neoplasms $[90,93]$.

The authors of a meta-analysis of prospective observational studies estimated that in postmenopausal women, with an increase in body mass index (BMI) by $5 \mathrm{~kg} / \mathrm{m}^{2}$, the risk of developing breast cancer increases by 12\% [94]. Abdominal obesity as assessed as waist to hip circumference ratio (WHR) also shows a strong positive correlation with the risk of postmenopausal breast cancer [95].

In the analysis of the anthropometric measurements, including measurements of estrogen and serum estrogen metabolite levels, strong positive associations were found between the present BMI and estrogens in postmenopausal women who do not use hormone replacement therapy [96].

\section{Women's knowledge about breast cancer prevention}

The credibility of messages promoting physical activity as a factor preventing heart disease and breast cancer was tested depending on the level of physical activity reported by participants. According to the surveyed women, it is easier to prevent and control heart disease than breast cancer. Moreover, physically active women are more susceptible to messages and prophylactic actions concerning the influence of physical activity on the prevention of breast cancer, compared to women who do not exercise. For this reason, innovative ways of reaching people who are not interested in physical activity need to be found [97].

\section{Conclusions}

Although the mechanism underlying the relationship between exercise and breast cancer risk remains unclear, the majority of randomized controlled trials conducted in healthy women showed a marked decrease in estradiol and progesterone induced by exercise. To date, evidence suggests that higher levels of endogenous estrogen are associated with an increased risk of breast cancer in both premenopausal and postmenopausal women; therefore, exercise contributes to reducing the risk of breast cancer and plays a key role in breast cancer management.

In summary, exercise decreases circulating sex hormones and reduces breast tumor growth by promoting changes in apoptosis and cell proliferation, and is therefore a safe intervention with undeniable benefits for women - regardless of the status of menopause and exercise-induced weight loss.

Current recommendations for physical activity include 150 to 300 minutes of moderate-intensity physical activity per week, or 75 to 150 minutes of high-intensity physical activity and some muscle-strengthening activity for at least 2 days a week [3]. Based on the available literature, a comprehensive and multidisciplinary approach is recommended that should include physical activity, weight control, a high fruit and vegetable intake, and a reduced dietary fat intake.

The process of carcinogenesis and the subsequent development of human neoplasia takes many years, so educational campaigns are needed to inform young women about the risk of breast cancer and how they can reduce it in the future. Prevention programs are also needed to motivate women to engage in health protective behaviors, including physical activity, to reduce their risk of breast cancer. It may be helpful to find innovative ways to target people who are not interested in physical activity [97].

\section{Conflict of interest: none declared}

\author{
Kinga Słojewska \\ Jagiellonian University Collegium Medicum \\ Doctoral School of Medical and Health Sciences \\ Faculty of Health Sciences \\ Department of Environmental Health \\ ul. Skawińska 8 \\ 31-066 Kraków, Poland \\ e-mail:kinga.slojewska@doctoral.uj.edu.pl
}

Received: 13 Aug 2021

Accepted: 12 Oct 2021

\section{References}

1. Friedenreich $\mathrm{CM}$. The role of physical activity in breast cancer etiology. Semin Oncol. 2010; 37(3): 297-302, doi: 10.1053/j.seminoncol.2010.05.008, indexed in Pubmed: 20709211.

2. Lee IM, Shiroma EJ, Lobelo F, et al. Lancet Physical Activity Series Working Group. Effect of physical inactivity on major non-communicable diseases worldwide: an analysis of burden of disease and life expectancy. Lancet. 2012; 380(9838): 219-229, doi: 10.1016/S01406736(12)61031-9, indexed in Pubmed: 22818936. 
3. Rock CL, Thomson C, Gansler T, et al. American Cancer Society guideline for diet and physical activity for cancer prevention. CA Cancer J Clin. 2020; 70(4): 245-271, doi: 10.3322/caac.21591, indexed in Pubmed: 32515498.

4. Sung H, Ferlay J, Siegel RL, et al. Global Cancer Statistics 2020: GLOBOCAN Estimates of Incidence and Mortality Worldwide for 36 Cancers in 185 Countries. CA Cancer J Clin. 2021; 71(3): 209-249, doi: 10.3322/ caac.21660, indexed in Pubmed: 33538338.

5. Ferlay J, Colombet M, Soerjomataram I, et al. Cancer statistics for the year 2020: An overview. Int J Cancer. 2021 [Epub ahead of print], doi: 10.1002/ijc.33588, indexed in Pubmed: 33818764.

6. Lauby-Secretan B, Scoccianti C, Loomis D, et al. International Agency for Research on Cancer Handbook Working Group. Body Fatness and Cancer--Viewpoint of the IARC Working Group. N Engl J Med. 2016; 375(8): 794-798, doi: 10.1056/NEJMsr1606602, indexed in Pubmed: 27557308.

7. Key J, Hodgson S, Omar RZ, et al. Meta-analysis of studies of alcohol and breast cancer with consideration of the methodological issues. Cancer Causes Control. 2006; 17(6): 759-770, doi: 10.1007/s10552-006-0011-0, indexed in Pubmed: 16783604.

8. Godinho-Mota JC, Gonçalves LV, Mota JF, et al. Sedentary Behavior and Alcohol Consumption Increase Breast Cancer Risk Regardless of Menopausal Status: A Case-Control Study. Nutrients. 2019; 11(8), doi: 10.3390/nu1 1081871, indexed in Pubmed: 31408930.

9. Eliassen AH, Missmer SA, Tworoger SS, et al. Endogenous steroid hormone concentrations and risk of breast cancer among premenopausal women. J Natl Cancer Inst. 2006; 98(19): 1406-1415, doi: 10.1093/jnci/ djj376, indexed in Pubmed: 17018787.

10. Kelsey JL, Gammon MD, John EM. Reproductive factors and breast cancer. Epidemiol Rev. 1993; 15(1): 36-47, doi: 10.1093/oxfordjournals. epirev.a036115, indexed in Pubmed: 8405211.

11. Armstrong $\mathrm{K}$, Eisen $\mathrm{A}$, Weber B. Assessing the risk of breast cancer. N Engl J Med. 2000; 342(8): 564-571, doi: 10.1056/NEJM200002243420807, indexed in Pubmed: 10684916.

12. Pike MC, Krailo MD, Henderson BE, et al.,Hormonal'risk factors,, breast tissue age' and the age-incidence of breast cancer. Nature. 1983; 303(5920): 767-770, doi: 10.1038/303767a0, indexed in Pubmed: 6866078.

13. Kamińska M, Ciszewski T, Łopacka-Szatan K, et al. Breast cancer risk factors. Prz Menopauzalny. 2015; 14(3): 196-202, doi: 10.5114/ pm.2015.54346, indexed in Pubmed: 26528110.

14. McPherson K, Steel CM, Dixon JM. ABC of breast diseases. Breast cancer-epidemiology, risk factors, and genetics. BMJ. 2000; 321(7261): 624628, doi: 10.1136/bmj.321.7261.624, indexed in Pubmed: 10977847.

15. Russo J, Russo $\mathrm{IH}$. Toward a physiological approach to breast cancer prevention. Cancer epidemiology, biomarkers \& prevention: a publication of the American Association for Cancer Research, cosponsored by the American Society of Preventive Oncology. 1994; 3(4): 353-364.

16. Lange CA, Yee D. Progesterone and breast cancer. Womens Health (Lond). 2008; 4(2): 151-162, doi: 10.2217/17455057.4.2.151, indexed in Pubmed: 19072517.

17. Ismail PM, Amato P, Soyal SM, et al. Progesterone involvement in breast development and tumorigenesis--as revealed by progesterone receptor "knockout" and „,knockin" mouse models. Steroids. 2003; 68(10-13): 779787, doi: 10.1016/s0039-128x(03)00133-8, indexed in Pubmed: 14667968.

18. Micheli A, Muti P, Secreto G, et al. Endogenous sex hormones and subsequent breast cancer in premenopausal women. Int J Cancer. 2004; 112(2): 312-318, doi: 10.1002/ijc.20403, indexed in Pubmed: 15352045.

19. Kossman DA, Williams NI, Domchek SM, et al. Exercise lowers estrogen and progesterone levels in premenopausal women at high risk of breast cancer. J Appl Physiol (1985). 2011; 111(6): 1687-1693, doi: 10.1152/ japplphysiol.00319.2011, indexed in Pubmed: 21903887.

20. Green J, Reeves GK, Floud S, et al. Million Women Study Collaborators, Million Women Study Collaborators, Million Women Study Collaborators, Million Women Study Collaboration, Million Women Study Collaborators, Million Women Study Collaborators, Million Women Study Collaborators. Breast cancer and hormone-replacement therapy in the Million Women Study. Lancet. 2003; 362(9382): 419-427, doi: 10.1016/ s0140-6736(03)14065-2, indexed in Pubmed: 12927427.

21. Kaaks R, Berrino F, Key T, et al. Serum sex steroids in premenopausal women and breast cancer risk within the European Prospective Investigation into Cancer and Nutrition (EPIC). J Natl Cancer Inst. 2005; 97(10): 755-765, doi: 10.1093/jnci/dji132, indexed in Pubmed: 15900045.

22. Knochenhauer ES, Boots LR, Potter HD, et al. Differential binding of estradiol and testosterone to SHBG. Relation to circulating estradiol levels. J Reprod Med. 1998; 43(8): 665-670, indexed in Pubmed: 9749416.

23. Fortunati N, Catalano MG. Sex hormone-binding globulin (SHBG) and estradiol cross-talk in breast cancer cells. Horm Metab Res. 2006; 38(4): 236-240, doi: 10.1055/s-2006-925337, indexed in Pubmed: 16700004.
24. Lynch BM, Neilson HK, Friedenreich CM. Physical activity and breast cancer prevention. Recent Results Cancer Res. 2011; 186: 13-42, doi: 10.1007/978-3-642-04231-7_2, indexed in Pubmed: 21113759.

25. McTiernan A. Mechanisms linking physical activity with cancer. Nat Rev Cancer. 2008; 8(3): 205-211, doi: 10.1038/nrc2325, indexed in Pubmed: 18235448.

26. Yu H, Rohan T. Role of the insulin-like growth factor family in cancer development and progression. J Natl Cancer Inst. 2000; 92(18): 1472-1489, doi: 10.1093/jnci/92.18.1472, indexed in Pubmed: 10995803.

27. Jasienska G, Ziomkiewicz A, Thune I, et al. Habitual physical activity and estradiol levels in women of reproductive age. Eur J Cancer Prev. 2006; 15(5): 439-445, doi: 10.1097/00008469-200610000-00009, indexed in Pubmed: 16912573.

28. Friedenreich CM, Orenstein MR. Physical activity and cancer prevention: etiologic evidence and biological mechanisms. J Nutr. 2002; 132(11 Suppl): 3456S-3464S, doi: 10.1093/jn/132.11.3456S, indexed in Pubmed: 12421870.

29. Samavat $\mathrm{H}$, Kurzer MS. Estrogen metabolism and breast cancer. Cancer Lett. 2015; 356(2 Pt A): 231-243, doi: 10.1016/j.canlet.2014.04.018, indexed in Pubmed: 24784887.

30. Kabuto M, Akiba S, Stevens RG, et al. A prospective study of estradiol and breast cancer in Japanese women. Cancer Epidemiol Biomarkers Prev. 2000; 9(6): 575-579, indexed in Pubmed: 10868691.

31. Key TJ, Appleby PN, Reeves GK, et al. Endogenous Hormones and Breast Cancer Collaborative Group. Sex hormones and risk of breast cancer in premenopausal women: a collaborative reanalysis of individual participant data from seven prospective studies. Lancet Oncol. 2013; 14(10): 1009-1019, doi: 10.1016/S1470-2045(13)70301-2, indexed in Pubmed: 23890780.

32. De Souza MJ, Miller BE, Loucks AB, et al. High frequency of luteal phase deficiency and anovulation in recreational women runners: blunted elevation in follicle-stimulating hormone observed during luteal-follicular transition. J Clin Endocrinol Metab. 1998; 83(12): 4220-4232, doi: 10.1210/jcem.83.12.5334, indexed in Pubmed: 9851755.

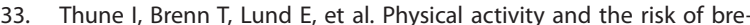
ast cancer. N Engl J Med. 1997; 336(18): 1269-1275, doi: 10.1056/ NEJM199705013361801, indexed in Pubmed: 9113929.

34. El-Lithy A, El-Mazny A, Sabbour A, et al. Effect of aerobic exercise on premenstrual symptoms, haematological and hormonal parameters in young women. J Obstet Gynaecol. 2015; 35(4): 389-392, doi: 10.3109/01443615.2014.960823, indexed in Pubmed: 25279689.

35. Verloop J, Rookus MA, van der Kooy K, et al. Physical activity and breast cancer risk in women aged 20-54 years. J Natl Cancer Inst. 2000; 92(2): 128-135, doi: 10.1093/jnci/92.2.128, indexed in Pubmed: 10639514.

36. Bullen BA, Skrinar GS, Beitins IZ, et al. Induction of menstrual disorders by strenuous exercise in untrained women. N Engl J Med. 1985; 312(21): 1349-1353, doi: 10.1056/NEJM198505233122103, indexed in Pubmed: 3990734.

37. Williams NI, Reed JL, Leidy HJ, et al. Estrogen and progesterone exposure is reduced in response to energy deficiency in women aged 25-40 years. Hum Reprod. 2010; 25(9): 2328-2339, doi: 10.1093/humrep/ deq172, indexed in Pubmed: 20605898.

38. Smith AJ, Phipps WR, Arikawa AY, et al. Effects of aerobic exercise on premenopausal sex hormone levels: results of the WISER study, a randomized clinical trial in healthy, sedentary, eumenorrheic women. Cancer Epidemiol Biomarkers Prev. 2011; 20(6): 1098-1106, doi: 10.1158/10559965.EPI-10-1219, indexed in Pubmed: 21467231.

39. Jasienska G, Ellison PT. Energetic factors and seasonal changes in ovarian function in women from rural Poland. Am J Hum Biol. 2004; 16(5):563-580, doi: 10.1002/ajhb.20063, indexed in Pubmed: 15368604.

40. Jasieńska G, Ellison PT. Physical work causes suppression of ovarian function in women. Proc Biol Sci. 1998; 265(1408): 1847-1851, doi: 10.1098/rspb.1998.0511, indexed in Pubmed: 9802241.

41. Ennour-Idrissi K, Maunsell E, Diorio C. Effect of physical activity on sex hormones in women: a systematic review and meta-analysis of randomized controlled trials. Breast Cancer Res. 2015; 17(1): 139, doi: 10.1186/s13058-015-0647-3, indexed in Pubmed: 26541144.

42. Williams $\mathrm{NI}$, Leidy HJ, Hill BR, et al. Magnitude of daily energy deficit predicts frequency but not severity of menstrual disturbances associated with exercise and caloric restriction. Am J Physiol Endocrinol Metab. 2015; 308(1): E29-E39, doi: 10.1152/ajpendo.00386.2013, indexed in Pubmed: 25352438.

43. Lieberman JL, DE Souza MJ, Wagstaff DA, et al. Menstrual Disruption with Exercise Is Not Linked to an Energy Availability Threshold. Med Sci Sports Exerc. 2018; 50(3): 551-561, doi: 10.1249/ MSS.0000000000001451, indexed in Pubmed: 29023359. 
44. Kabat GC, Chang CJ, Sparano JA, et al. Urinary estrogen metabolites and breast cancer: a case-control study. Cancer Epidemiol Biomarkers Prev. 1997; 6(7): 505-509, indexed in Pubmed: 9232337.

45. Campbell KL, Westerlind KC, Harber VJ, et al. Associations between aerobic fitness and estrogen metabolites in premenopausal women. Med Sci Sports Exerc. 2005; 37(4): 585-592, doi: 10.1249/01. mss.0000158185.23595.24, indexed in Pubmed: 15809556.

46. Bentz AT, Schneider CM, Westerlind KC. The relationship between physical activity and 2-hydroxyestrone, 16alpha-hydroxyestrone, and the $2 / 16$ ratio in premenopausal women (United States). Cancer Causes Control. 2005; 16(4):455-461, doi: 10.1007/s10552-004-6256-6, indexed in Pubmed: 15953988.

47. Pasagian-Macaulay A, Meilahn EN, Bradlow HL, et al. Urinary markers of estrogen metabolism 2- and 16 alpha-hydroxylation in premenopausal women. Steroids. 1996; 61(8): 461-467, doi: 10.1016/0039-128x(96)00089-x, indexed in Pubmed: 8870165

48. Campbell KL, Westerlind KC, Harber VJ, et al. Effects of aerobic exercise training on estrogen metabolism in premenopausal women: a randomized controlled trial. Cancer Epidemiol Biomarkers Prev. 2007; 16(4): 731-739, doi: 10.1158/1055-9965.EPI-06-0784, indexed in Pubmed: 17416764.

49. Speroff L, Glass RH. Clinical Gynecologic Endocrinology and Infertility 6th ed. Lippincott Williams \& Wilkins 1999.

50. Powell L. Too much of a good thing: female athlete triad. Mo Med. 2011; 108(3): 176-178, indexed in Pubmed: 21736076.

51. Horn E, Gergen N, McGarry KA. The female athlete triad. RI Med J (2013). 2014; 97(11): 18-21, indexed in Pubmed: 25365814.

52. De Souza MJ, Hontscharuk R, Olmsted M, et al. Physiological aspects and clinical sequelae of energy deficiency and hypoestrogenism in exercising women. Hum Reprod Update. 2004; 10(5): 433-448, doi: 10.1093/humupd/dmh033, indexed in Pubmed: 15231760.

53. Morris FL, Wark JD. An effective, economic way of monitoring menstrual cycle hormones in at risk female athletes. Med Sci Sports Exerc. 2001; 33(1): 9-14, doi: 10.1097/00005768-200101000-00003, indexed in Pubmed: 11194117

54. Morris FL, Payne WR, Wark JD. Prospective decrease in progesterone concentrations in female lightweight rowers during the competition season compared with the off season: a controlled study examining weight loss and intensive exercise. Br J Sports Med. 1999; 33(6): 417-422, doi: 10.1136/bjsm.33.6.417, indexed in Pubmed: 10597853.

55. Cho GJ, Han SW, Shin JH, et al. Effects of intensive training on menstrual function and certain serum hormones and peptides related to the female reproductive system. Medicine (Baltimore). 2017; 96(21): e6876, doi: 10.1097/MD.0000000000006876, indexed in Pubmed: 28538378.

56. Diet, nutrition, physical activity and breast cancer. American Institute for Cancer Research 2018. http://www.wcrforg/sites/default/files/ Prostate-Cancer-2014-Report.pdf\%0Ahttp://www.aicr.org/continuous-update-project/reports/breast-cancer-report-2017.pdf\%0Adietandcancerreport.org.

57. Borch KB, Braaten T, Lund E, et al. Physical activity before and after breast cancer diagnosis and survival - the Norwegian women and cancer cohort study. BMC Cancer. 2015; 15: 967, doi: 10.1186/s12885015-1971-9, indexed in Pubmed: 26672980.

58. Irwin ML, Smith AW, McTiernan A, et al. Influence of pre- and postdiagnosis physical activity on mortality in breast cancer survivors: the health, eating, activity, and lifestyle study. J Clin Oncol. 2008; 26(24): 3958-3964, doi: 10.1200/JCO.2007.15.9822, indexed in Pubmed: 18711185.

59. Chlebowski RT, Aiello E, McTiernan A. Weight loss in breast cancer patient management. J Clin Oncol. 2002; 20(4): 1128-1143, doi: 10.1200/ JCO.2002.20.4.1128, indexed in Pubmed: 11844838.

60. Lahart IM, Metsios GS, Nevill AM, et al. Physical activity, risk of death and recurrence in breast cancer survivors: A systematic review and meta-analysis of epidemiological studies. Acta Oncol. 2015; 54(5): 635-654, doi: 10.3109/0284186X.2014.998275, indexed in Pubmed: 25752971.

61. Biganzoli E, Desmedt C, Demicheli R. Does Physical Activity Have an Impact on Recurrence Dynamics in Early Breast Cancer Patients? J Clin Med. 2021; 10(4), doi: 10.3390/jcm10040831, indexed in Pubmed: 33670615.

62. Savolainen-Peltonen $\mathrm{H}$, Vihma V, Leidenius M, et al. Breast Adipose Tissue Estrogen Metabolism in Postmenopausal Women With or Without Breast Cancer. J Clin Endocrinol Metab. 2014; 99(12): E2661-E2667, doi: 10.1210/jc.2014-2550.

63. Stone SA, Han CJ, Senn T, et al. Sex Hormones in Women With Elevated Breast Cancer Risk Undergoing Weight Loss. West J Nurs Res. 2019;
41(11): 1602-1622, doi: 10.1177/0193945918820672, indexed in Pubmed: 30616442.

64. Kossman DA, Williams NI, Domchek SM, et al. Exercise lowers estrogen and progesterone levels in premenopausal women at high risk of breast cancer. J Appl Physiol (1985). 2011; 111(6): 1687-1693, doi: 10.1152/ japplphysiol.00319.2011, indexed in Pubmed: 21903887.

65. Jasienska G, Ziomkiewicz A, Thune I, et al. Habitual physical activity and estradiol levels in women of reproductive age. Eur J Cancer Prev. 2006; 15(5): 439-445, doi: 10.1097/00008469-200610000-00009, indexed in Pubmed: 16912573.

66. Howard RA, Leitzmann MF, Linet MS, et al. Physical activity and breast cancer risk among pre- and postmenopausal women in the U.S. Radiologic Technologists cohort. Cancer Causes Control. 2009; 20(3): 323-333, doi: 10.1007/s10552-008-9246-2, indexed in Pubmed: 18941914.

67. Ghosn B, Benisi-Kohansal S, Ebrahimpour-Koujan S, et al. Association between healthy lifestyle score and breast cancer. Nutr J. 2020; 19(1): 4, doi: 10.1186/s12937-020-0520-9, indexed in Pubmed: 31937325.

68. Furberg AS, Jasienska G, Bjurstam N, et al. Metabolic and hormonal profiles: $\mathrm{HDL}$ cholesterol as a plausible biomarker of breast cancer risk. The Norwegian EBBA Study. Cancer Epidemiol Biomarkers Prev. 2005; 14(1): 33-40, indexed in Pubmed: 15668473.

69. Kapiszewska M, Miskiewicz M, Ellison PT, et al. High tea consumption diminishes salivary 17beta-estradiol concentration in Polish women. Br J Nutr. 2006; 95(5): 989-995, doi: 10.1079/bjn20061755, indexed in Pubmed: 16611391.

70. Rosendahl AH, Perks CM, Zeng Li, et al. Caffeine and Caffeic Acid Inhibit Growth and Modify Estrogen Receptor and Insulin-like Growth Factor I Receptor Levels in Human Breast Cancer. Clin Cancer Res. 2015; 21 (8): 1877-1887, doi: 10.1158/1078-0432.CCR-14-1748, indexed in Pubmed: 25691730.

71. Kiyama R. Estrogenic Activity of Coffee Constituents. Nutrients. 2019; 11(6), doi: 10.3390/nu11061401, indexed in Pubmed: 31234352.

72. Finstad SE, Emaus A, Potischman N, et al. Influence of birth weight and adult body composition on 17beta-estradiol levels in young women. Cancer Causes Control. 2009; 20(2): 233-242, doi: 10.1007/s10552-0089238-2, indexed in Pubmed: 18853264.

73. Kloss JD, Perlis ML, Zamzow JA, et al. Sleep, sleep disturbance, and fertility in women. Sleep Med Rev. 2015; 22: 78-87, doi: 10.1016/j. smrv.2014.10.005, indexed in Pubmed: 25458772

74. Merklinger-Gruchala A, Ellison PT, Lipson SF, et al. Low estradiol levels in women of reproductive age having low sleep variation. Eur J Cancer Prev. 2008; 17(5): 467-472, doi: 10.1097/CEJ.0b013e3282f75f67, indexed in Pubmed: 18714190.

75. Sowers MF, Zheng H, Kravitz HM, et al. Sex steroid hormone profiles are related to sleep measures from polysomnography and the Pittsburgh Sleep Quality Index. Sleep. 2008; 31(10): 1339-1349, indexed in Pubmed: 18853931

76. Healy GN, Matthews CE, Dunstan DW, et al. Sedentary time and cardio-metabolic biomarkers in US adults: NHANES 2003-06. Eur Heart J. 2011; 32(5): 590-597, doi: 10.1093/eurheartj/ehq451, indexed in Pubmed: 21224291.

77. Lynch BM. Sedentary behavior and cancer: a systematic review of the literature and proposed biological mechanisms. Cancer Epidemiol Biomarkers Prev. 2010; 19(11): 2691-2709, doi: 10.1158/1055-9965. EPI-10-0815, indexed in Pubmed: 20833969.

78. Ravi S, Kujala UM, Tammelin TH, et al. Adolescent Sport Participation and Age at Menarche in Relation to Midlife Body Composition, Bone Mineral Density, Fitness, and Physical Activity. J Clin Med. 2020; 9(12), doi: 10.3390/jcm9123797, indexed in Pubmed: 33255351.

79. Calthorpe L, Brage S, Ong KK. Systematic review and meta-analysis of the association between childhood physical activity and age at menarche. Acta Paediatr. 2019; 108(6): 1008-1015, doi: 10.1111/apa.14711, indexed in Pubmed: 30588652.

80. Al-Azzawi F, Palacios S. Hormonal changes during menopause. Maturitas. 2009; 63(2): 135-137, doi: 10.1016/j.maturitas.2009.03.009, indexed in Pubmed: 19372016.

81. Bertone-Johnson ER, Tworoger SS, Hankinson SE. Recreational physical activity and steroid hormone levels in postmenopausal women. Am J Epidemiol. 2009; 170(9): 1095-1104, doi: 10.1093/aje/kwp254, indexed in Pubmed: 19783585.

82. Santoro N, Brown JR, Adel T, et al. Characterization of reproductive hormonal dynamics in the perimenopause. J Clin Endocrinol Metab. 1996; 81(4): 1495-1501, doi: 10.1210/jcem.81.4.8636357, indexed in Pubmed: 8636357

83. Robles Gil MC, Timón R, Toribio AF, et al. Effects of aerobic exercise on urinary estrogens and progestagens in pre and postmenopausal 
women. Eur J Appl Physiol. 2012; 112(1): 357-364, doi: 10.1007/s00421011-1982-4, indexed in Pubmed: 21559948.

84. Key TJ, Appleby PN, Reeves GK, et al. Endogenous Hormones and Breast Cancer Collaborative Group. Circulating sex hormones and breast cancer risk factors in postmenopausal women: reanalysis of 13 studies. Br J Cancer. 2011; 105(5): 709-722, doi: 10.1038/bjc.2011.254, indexed in Pubmed: 21772329.

85. Dallal CM, Brinton LA, Matthews CE, et al. Association of Active and Sedentary Behaviors with Postmenopausal Estrogen Metabolism. Med Sci Sports Exerc. 2016; 48(3): 439-448, doi: 10.1249/ MSS.0000000000000790, indexed in Pubmed: 26460631.

86. Dallal CM, Tice JA, Buist DSM, et al. B FIT Research Group. Estrogen metabolism and breast cancer risk among postmenopausal women: a case-cohort study within B FIT. Carcinogenesis. 2014; 35(2): 346-355, doi: 10.1093/carcin/bgt367, indexed in Pubmed: 24213602

87. Zhu BT, Conney AH. Functional role of estrogen metabolism in target cells: review and perspectives. Carcinogenesis. 1998; 19(1): 1-27, doi: 10.1093/carcin/19.1.1, indexed in Pubmed: 9472688.

88. Neilson HK, Friedenreich CM, Brockton NT, et al. Physical activity and postmenopausal breast cancer: proposed biologic mechanisms and areas for future research. Cancer Epidemiol Biomarkers Prev. 2009; 18(1): 11-27, doi: 10.1158/1055-9965.EPI-08-0756, indexed in Pubmed: 19124476.

89. van Kruijsdijk RCM, van der Wall E, Visseren FLJ. Obesity and cancer: the role of dysfunctional adipose tissue. Cancer Epidemiol Biomarkers Prev. 2009; 18(10): 2569-2578, doi: 10.1158/1055-9965.EPI-09-0372, indexed in Pubmed: 19755644.

90. CAULEY J, GUTAI J, KULLER L, et al. THE EPIDEMIOLOGY OF SERUM SEX HORMONES IN POSTMENOPAUSAL WOMEN. American Journal of Epidemiology. 1989; 129(6): 1120-1131, doi: 10.1093/oxfordjournals. aje.a115234.
91. Lukanova A, Lundin E, Zeleniuch-Jacquotte A, et al. Body mass index, circulating levels of sex-steroid hormones, IGF-I and IGF-binding protein-3: a cross-sectional study in healthy women. Eur J Endocrinol. 2004; 150(2): 161-171, doi: 10.1530/eje.0.1500161, indexed in Pubmed: 14763914.

92. Enger SM, Ross RK, Paganini-Hill A, et al. Body size, physical activity, and breast cancer hormone receptor status: results from two case-control studies. Cancer Epidemiol Biomarkers Prev. 2000; 9(7):681-687, indexed in Pubmed: 10919738

93. Key TJ, Appleby PN, Reeves GK, et al. Endogenous Hormones Breast Cancer Collaborative Group. Body mass index, serum sex hormones, and breast cancer risk in postmenopausal women. J Natl Cancer Inst. 2003; 95(16): 1218-1226, doi: 10.1093/jnci/djg022, indexed in Pubmed: 12928347.

94. Renehan A, Tyson M, Egger M, et al. Body-mass index and incidence of cancer: a systematic review and meta-analysis of prospective observational studies. The Lancet. 2008; 371(9612): 569-578, doi: 10.1016/ s0140-6736(08)60269-x.

95. Aune D, Rosenblatt DAN, Chan D, et al. Anthropometric factors and endometrial cancer risk: a systematic review and dose-response meta-analysis of prospective studies. Annals of Oncology. 2015; 26(8): 1635-1648, doi: 10.1093/annonc/mdv142.

96. Oh H, Coburn SB, Matthews CE, et al. Anthropometric measures and serum estrogen metabolism in postmenopausal women: the Women's Health Initiative Observational Study. Breast Cancer Res. 2017; 19(1): 28, doi: 10.1186/s13058-017-0810-0, indexed in Pubmed: 28284224

97. Berry TR, Jones KE, Courneya KS, et al. Believability of messages about preventing breast cancer and heart disease through physical activity. BMC Psychol. 2018; 6(1): 2, doi: 10.1186/s40359-018-0213-8, indexed in Pubmed: 29347973. 